The University of Maine

DigitalCommons@UMaine

$1-1-2004$

\title{
Optical modeling of ocean waters: Is the case 1 - case 2 classification still useful?
}

Curtis D. Mobley

Sequoia Scientific, Inc.

Dariusz Stramski

Marine Physical Laboratory

W. Paul Bissett

Florida Environmental Research Institute

Emmanuel Boss

University of Maine, emmanuel.boss@maine.edu

Follow this and additional works at: https://digitalcommons.library.umaine.edu/sms_facpub

Part of the Marine Biology Commons

\section{Repository Citation}

Mobley, Curtis D.; Stramski, Dariusz; Paul Bissett, W.; and Boss, Emmanuel, "Optical modeling of ocean waters: Is the case 1 - case 2 classification still useful?" (2004). Marine Sciences Faculty Scholarship. 153.

https://digitalcommons.library.umaine.edu/sms_facpub/153

This Article is brought to you for free and open access by DigitalCommons@UMaine. It has been accepted for inclusion in Marine Sciences Faculty Scholarship by an authorized administrator of DigitalCommons@UMaine. For more information, please contact um.library.technical.services@maine.edu. 


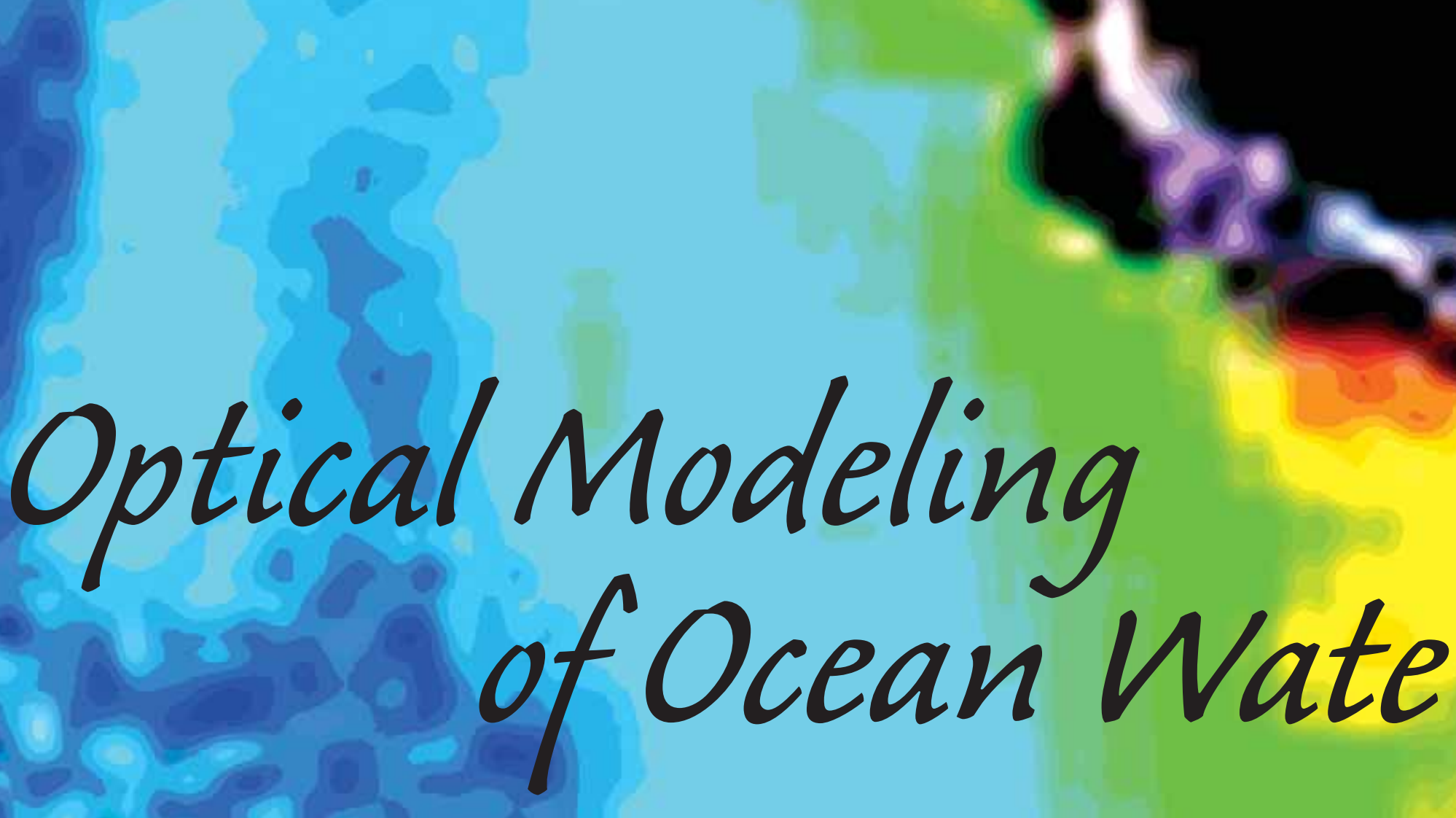

\section{Is the Case 1 - Case 2 Classification Still Useful?}

BY CURTIS D. MOBLEY, DARIUSZ STRAMSKI,

W. PAUL BISSETT, AND EMMANUEL BOSS 


\section{WHAT ARE CASE 1 AND CASE 2 WATERS?}

The classification of ocean waters into "Case 1" and "Case 2" began with Morel and Prieur (1977). They wrote that

...two extreme cases can be identified and separated. Case 1 is that of a concentration of phytoplankton high compared to other particles... In contrast, the inorganic particles are dominant in case 2.... In both cases dissolved yellow substance is present in variable amounts... An ideal case 1 would be a pure culture of phytoplankton and an ideal case 2 a suspension of nonliving material with a zero concentration of pigments.

Morel and Prieur emphasized that these ideal cases are not encountered in nature, and they suggested the use of high or low values of the ratio of pigment concentration to scattering coefficient as a basis for discriminating between Case 1 and Case 2 waters. Although no specific values of this ratio were proposed to serve as criteria for classification, their example data suggested that the ratio of chlorophyll a concentration (in $\mathrm{mg} \mathrm{m}^{-3}$ ) to the scattering coefficient at $550 \mathrm{~nm}$ (in m$~^{-1}$ ) in Case 1 waters is greater than 1 and in Case 2 waters is less than 1. Importantly, however, Morel and Prieur also showed data classified as “intermediate waters" with the ratio between about 1 and 2.2.

Although the original definition from 1977 did not imply a binary classification, the practice of most investigators in the following years clearly evolved toward a bipartite analysis. Neither the original criterion based on the ratio of pigment concentration to scattering coefficient, nor any other

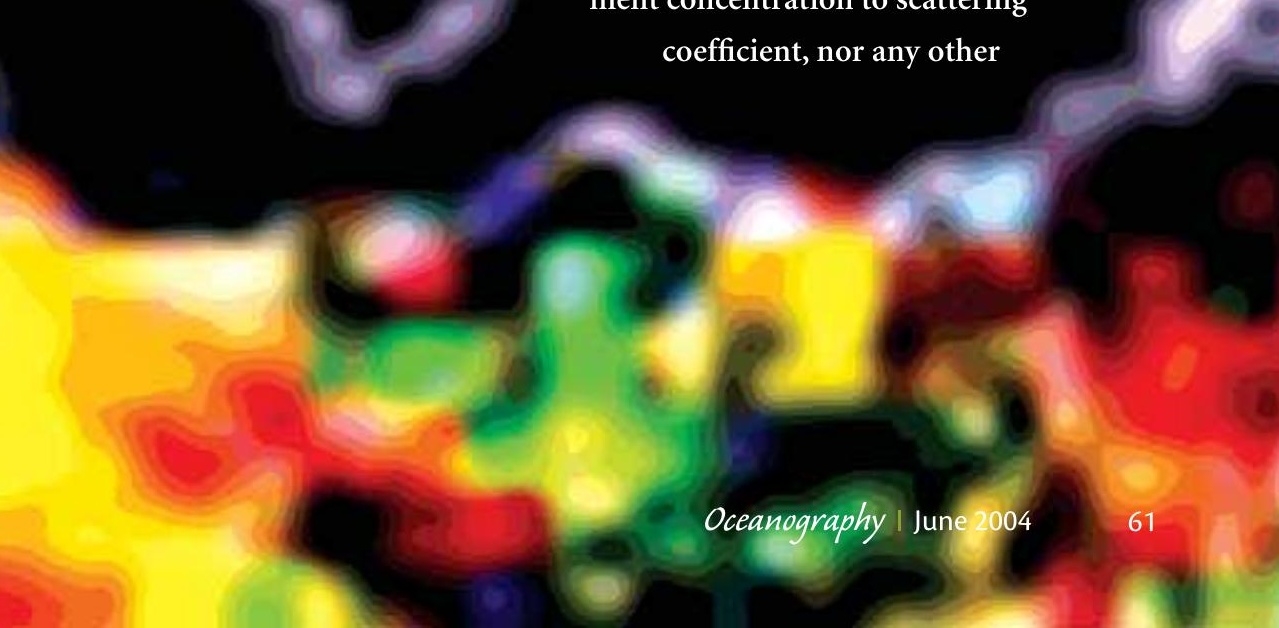


well-defined quantitative criterion, has been in common use, and the definitions of Case 1 and Case 2 have evolved into the ones commonly used today (Gordon and Morel, 1983; Morel, 1988):

- Case 1 waters are those waters whose optical properties are determined primarily by phytoplankton and related colored dissolved organic matter (CDOM) and detritus degradation products.

- Case 2 waters are everything else, namely waters whose optical properties are significantly influenced by other constituents such as mineral particles, CDOM, or microbubbles, whose concentrations do not covary with the phytoplankton concentration.

The origin of the optically relevant constituents in Case 1 water is biological activity in the water column. Smith and Baker (1978) introduced the concept of the "bio-optical state" of ocean waters to represent a measure of the effect of biological processes on ocean optical properties, and they indicated that the bio-optical state can be usefully related to the concentration of chlorophyll $a$ in water. Since then the chlorophyll concentration has been generally used as the proxy for phytoplankton and related water constituents in bio-optical models of Case 1 waters (e.g.,

Curtis D. Mobley (curtis.mobley@sequoiasci. com) is Vice President and Senior Scientist, Sequoia Scientific, Inc., Bellevue, WA. Dariusz Stramski is Professor of Oceanography, Marine Physical Laboratory, Scripps Institution of Oceanography, University of California at San Diego, La Jolla, CA. W. Paul Bissett is Research Scientist, Florida Environmental Research Institute, Tampa, FL. Emmanuel Boss is Assistant Professor, School of Marine Sciences, University of Maine, Orono, ME.
Morel, 1988). Various non-biological processes often generate Case 2 waters. Mineral particles can enter the water column from terrestrial runoff or erosion in coastal areas, aeolian transport of dust, or sediment resuspension by currents or dredging. Living phytoplankton can also generate mineral particles, such as the calcite coccoliths shed by coccolithophores. CDOM that is unrelated to biological activity in the water column can come from terrestrial runoff or benthic inputs from seagrass and corals. Air bubbles are injected into surface waters by breaking waves. Anthropogenic inputs such as pollutants or oil spills can cause Case 2 water in localized areas.

The Case 1 and 2 scheme is commonly used as a way to classify waters for modeling purposes. Thus bio-optical models have been developed for the prediction of inherent optical properties (IOPs, namely the absorption, scattering, and backscattering coefficients) in Case 1 waters. These models use the chlorophyll concentration as the input parameter needed to predict the IOPs of the water column. Other chlorophyll-based models have been developed for apparent optical properties (AOPs), namely reflectances (various ratios of upwelling to downwelling light) and diffuse attenuation functions (normalized depth derivatives, which show how the light changes with depth). Recent versions of such models for Case 1 waters are reviewed in Morel and Maritorena (2001). Regardless of whether IOPs or AOPs are involved, the chlorophyll-based bio-optical models are often used to estimate chlorophyll concentrations from optical measurements, for example, from satellite measurements of ocean color.
PROBLEMS WITH THE CASE 1 VS.

\section{CASE 2 CLASSIFICATION}

In the late 1970s and early 1980s the idealized concept of Case 1 water provided useful guidance for the development of the first generation of bio-optical models. In fact without the simple Case 1 idea that it is possible to estimate chlorophyll from optical measurements, we might not have had ocean color satellites and the associated scientific progress. Hence, the classification scheme rendered a huge service to the bio-optical oceanography and ocean color remote-sensing communities. However, the continued use of Case 1 and Case 2 today is no longer helping us solve the remaining scientific problems. In truth, this classification scheme may bring ambiguity, confusion, misuse, or an excuse for poor performance of algorithms. (Of course, any algorithm may fail in a particular application due to natural variability in optical properties and that failure is unrelated to how the optical properties are classified.)

There are many problems with the Case 1-Case 2 classification scheme. As noted by Morel and Prieur (1977) in their seminal paper, there is no sharp dividing line between Case 1 and 2 waters. Open-ocean waters dominated by phytoplankton are usually regarded as the archetypical example of Case 1 waters, but even there the CDOM concentration does not covary with the instantaneous chlorophyll concentration (Bricaud et al., 1981) because the CDOM concentration is influenced by past phytoplankton concentrations and photobleaching. Gordon et al. (1988) discussed the problem of coccolith concentrations causing very high scattering coefficients that do not covary with pigment concentrations; see also Balch et al. (2004). Phytoplankton pigments, as measured by 
chlorophyll concentration and commonly used as the basis for bio-optical models for Case 1 water, are a rather poor proxy for overall organic biomass or carbon biomass. The chlorophyll-to-carbon ratio for phytoplankton varies by a factor of five owing to light and nutrient history (which causes variability in pigment suites and pigment packaging) and geographic region and season (with associated variability in species composition). In addition, the ratio of chlorophyll to carbon biomass is also affected by the presence of organisms other than phytoplankton. Nor is there an unambiguous value that should be used for the chlorophyll concentration in bio-optical models. If the model is predicting an IOP as a function of depth, then the local chlorophyll concentration at each depth would be appropriate.

But if the model is predicting reflectance or diffuse attenuation, which incorporate light that has penetrated the upper part of the water column, then an appropriately weighted depth-averaged chlorophyll values may be more adequate.

It may not come as a surprise that even within the Case 1 classification, there is a factor-of-two (and sometimes much greater) variability in the values of optical properties for a given chlorophyll value. A good correlation between chlorophyll and an optical property on a global average does not imply good predictability in a particular situation. A squared correlation coefficient of $r^{2}$ $=0.9$ does not mean that we can predict the chlorophyll concentration to better than a factor of two, because the $r^{2}$ value is strongly influenced by the large dynamic range of the chlorophyll concentration. Even after decades of research, understanding and predicting the optical properties of Case 1 waters is still a work in progress (Loisel and
Morel, 1998; Morel et al., 2002; Maritorena et al., 2004).

The definitions of Case 1 and Case 2 were originally developed for optically deep waters. If we consider only the IOPs of the water itself, then the bottom is irrelevant in saying whether the water is Case 1 or 2 . However, if the bottom is shallow, bottomreflected light can be a very significant part of the total light field within and leaving a water body. Thus one can have a situation in which Case 1 bio-optical models adequately predict the IOPs, but Case 1 models for reflectance fail completely because of the contribution of bottom-reflected light. So in that sense, all optically shallow waters are Case 2, even if the water IOPs themselves are Case 1.

Nonabsorbing microbubbles or quartz particles can quickly cause a Case 1 model for scattering to fail, even though a Case 1 model for absorption continues to perform well. Is the water then Case 1 or Case 2? Such a contradictory situation is not just of academic interest. Figure 1 shows the absorption coefficients $a$ as measured over the course of a tidal cycle near Lee Stocking Island, Bahamas (these total IOPs include the contributions by water itself). This area has deep open ocean to the northeast and shallow (less than $10 \mathrm{~m}$ ) shoals to the west and south (see Figure 1 in Boss and Zaneveld, 2003). The flood tide brings in open-ocean water, which has chlorophyll concentrations near $0.2 \mathrm{mg} \mathrm{Chl} \mathrm{m}^{-3}$. The red curve in Figure 1 shows $a$ as predicted by a standard bio-optical model for Case 1 IOPs. The total absorption at high tide is very close to that for Case 1 water at wavelengths of $470 \mathrm{~nm}$ and greater. Below $470 \mathrm{~nm}$ there is some additional absorption in the blue. The ebb tide drains the extensive shallow areas, which are covered by sea grass beds, corals, and ooid sands. These benthic biota are a source of CDOM that is unrelated to the phytoplankton in the water (Boss and Zaneveld, 2003). The ebb tide thus carries CDOM-rich water, which greatly increases the absorption at blue wavelengths. Because of the benthic CDOM, the absorption coefficient varies by over a factor of three during a tidal cycle, with the highest CDOM concentration and absorption occurring at low tide.

Figure 2 shows the corresponding scattering coefficients $b$. The scattering coefficient is only about 30 percent larger at low tide

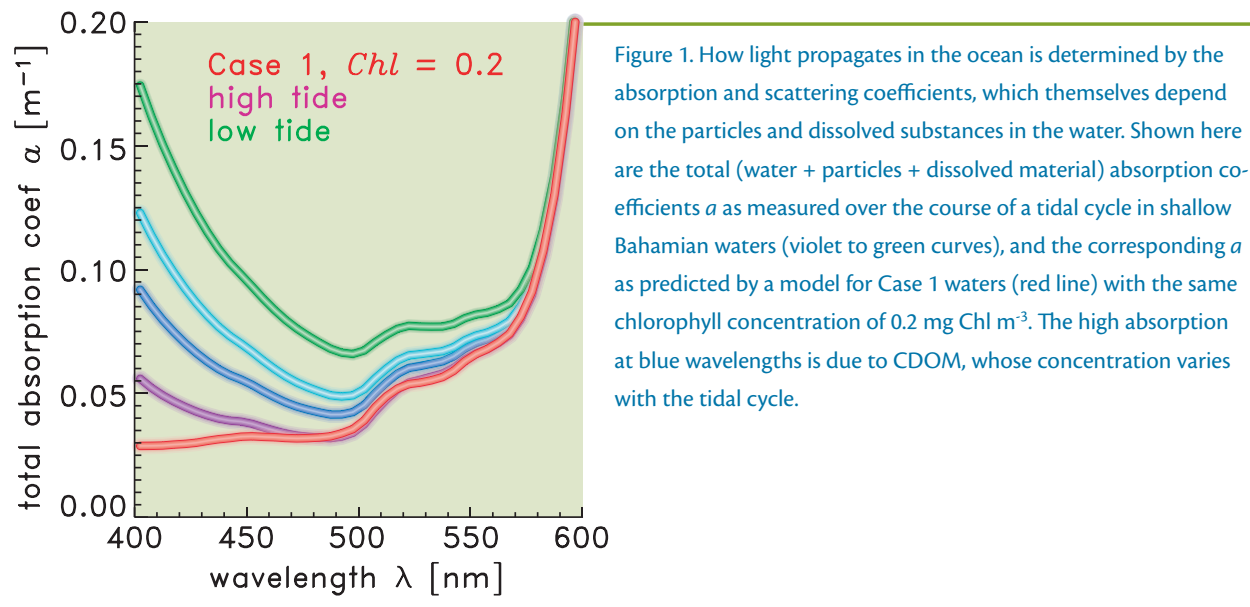




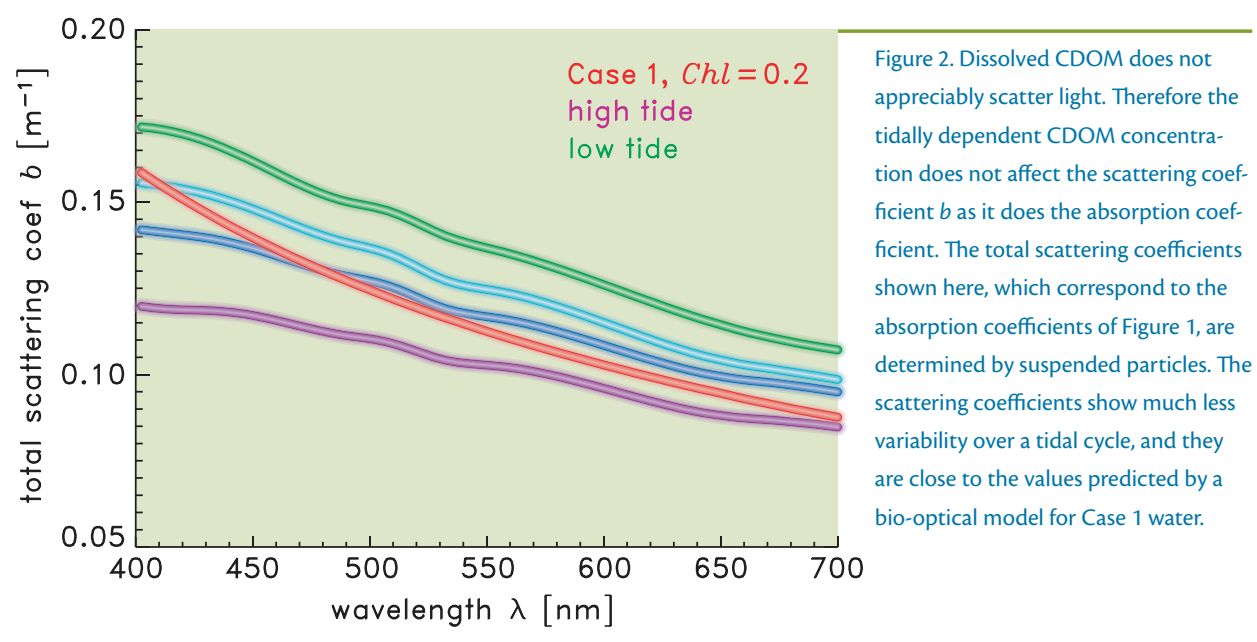

than at high tide, indicating that the ebb and flood of the tide has a smaller effect on the particulate load in the water than on the CDOM concentration. The scattering coefficient is close to that predicted by a Case 1 model throughout the tidal cycle. This implies that most of the scattering in the water column covaries with the phytoplankton concentration. Thus we see that in this particular water body, the absorption coefficient is strongly coupled to the tidal cycle and is much greater than for Case 1 water with the same chlorophyll concentration. The scattering coefficient, on the other hand, is much less variable, is weakly coupled to the tides, and is close to what would be expected in Case 1 water. The Case 1-Case 2 classification is of little value in describing this water body.

Given the human tendency to oversimplify and the attraction of an "either-or" classification, plus the weight of historical precedence, the Case 1 vs. 2 scheme still survives. Indeed, it is tempting to propose new definitions, which might allow us to retain the convenience of a binary classification while at the same time classify shallow waters or waters where a constituent (such as bubbles or terrigenous CDOM) influences absorption and scattering in different ways. Thus we might redefine Case 1 and 2 as fol- lows: An optical quantity is Case 1 if it can be adequately predicted from the water-column chlorophyll concentration; an optical quantity is Case 2 if it cannot be adequately predicted from the water-column chlorophyll concentration.

These straw-man definitions shift the determining quantity from being the water column to being the optical quantity of interest. This would allow an optically shallow water body to be modeled with Case 1 bio-optical models for the absorption and scattering coefficients while simultaneously could even use a Case 2 model for absorption and a Case 1 model for scattering, as would be appropriate for the data of Figures 1 and 2. However, these definitions suffer from many of the same problems as the classic definitions. What is the proper value of the chlorophyll concentration? How accurate is "adequate" prediction? If we decide that 30 percent accuracy for the absorption coefficient is acceptable, then a model that gives a 29 percent error would say that the water (or optical quantity) is Case 1, but a model that gives 31 percent error would say that it failed because the water (or optical quantity) was Case 2.

One important reason for the ambiguity using a Case 2 model for its reflectance. We of the Case 1-Case 2 classification is associated with strong spectral variations in the contribution of phytoplankton and other water constituents to any given optical property. For a given constituent, the spectral patterns of these contributions are not the same for different optical properties. Thus in some water body, the absorption coefficient might be classified as Case 1 near the red peak of chlorophyll but as Case 2 in the blue or violet-UV part of the spectrum because of the significant effect of CDOM on short-wavelength absorption. We see an example of this in the high-tide data of Figure 1 , where the absorption is well modeled as Case 1 above $470 \mathrm{~nm}$, but is Case 2 below $470 \mathrm{~nm}$.

There are also issues of rapid temporal fluctuations between Case 1 and Case 2. A breaking wave can inject bubbles that make the scattering Case 2. However, the bubbles dissipate within a few seconds, and the scattering is again Case 1. Then a few seconds later another wave breaks, and the scattering is again Case 2.

We are unable to formulate well-defined and scientifically justified quantitative criteria for unambiguously classifying a water body or optical property as either Case 1 or Case 2. Redefinition of Case 1 and Case 2 is the wrong path to follow. We therefore suggest that it is time simply to drop the Case 1-Case 2 classification and focus on modeling water bodies according to whatever constituents are in the water column and whatever the bottom boundary is.

\section{THE FUTURE OF OPTICAL MODELING}

If we are to progress beyond the oversimplification of modeling optical properties in terms of bulk parameters such as chlorophyll concentration, then we must view water as a complex mix of particles and dis- 
solved substances that produce optical variability over a continuum of values covering a broad range. We need to understand the optical properties of the myriad possible constituents of oceanic waters in terms of their individual characteristics. This requires understanding the complexities of how the same species of phytoplankton develop different optical properties according to their light and nutrient history; how different species of phytoplankton have much different optical properties even though they have the same chlorophyll concentration in a given water body; and how different mineral types or mixed assemblages of mineral types interact with light. Thus we have to account for optically important particle characteristics such as composition (particle type), internal structure, size distribution, and concentration. The fact that such complete information is seldom available today should not deter us from charting the proper course for future research; it should be an incentive for acquiring the needed information.

Work along these lines has been underway for some time. The optical properties of different plankton species are under study (e.g., Stramski and Mobley, 1997; Mobley and Stramski, 1997; Stramski et al., 2001).
Recent work by Babin et al. (2003), Babin and Stramski (2004), and Stramski et al. (2004) represent the type of research needed to quantify the optical properties of mineral particles. Coupled physical-biological-optical models are now under development in which the components are modeled by various functional groups (Prochlorococcus, Synechococcus, large diatoms, small diatoms, detritus, etc.; Bissett et al., 1999a, 1999b), and each functional group is modeled with different particle absorption and scattering properties.

Regardless of whether we retain the traditional Case 1 - Case 2 definitions or view water as a complex mix of particles and dissolved substances, mineral particles from terrigenous runoff or sediment resuspension are a common cause for the failure of (traditional Case 1) bio-optical models. Figure 3 shows an example of the large effect that resuspended sediments can have on the remote-sensing reflectance $R_{r s}$ as seen in a satellite image from SeaWiFS sensor. The left panel shows the SeaWiFS $R_{r s}$ at $443 \mathrm{~nm}$ for the West Florida Shelf on June 8, 1998, when the water was generally Case 1 . The right panel is the same scene on November 8, 1998, after Tropical Storm Mitch passed over
Florida. The high reflectance (red area) at the right of the figure is believed to be due to increased scattering by storm-resuspended sediments in these shallow waters.

Mineral particles have absorption and scattering properties that are much different than those of phytoplankton. Thus there are significant differences in the water optical properties when mineral particle concentrations are high. Figure 4 shows example mass-specific absorption spectra for minerals, compared with a typical chlorophyllspecific spectrum for phytoplankton. As seen there, mineral particles are often highly absorbing in the blue and do not display the chlorophyll absorption bands seen in phytoplankton. Figure 5 shows the corresponding mass-specific scattering spectra. As with absorption, mineral scattering can be much different than phytoplankton scattering.

Continued progress in ocean color science requires the ability to understand both the IOPs and the water-leaving radiance or remote-sensing reflectance for any water body (Bissett et al., 2002). Figure 6 shows the remote-sensing reflectance $R_{r s}$ as predicted by Hydrolight (a radiative transfer numerical model) using the IOPs of Figures 1 and 2 (more information on Hydrolight
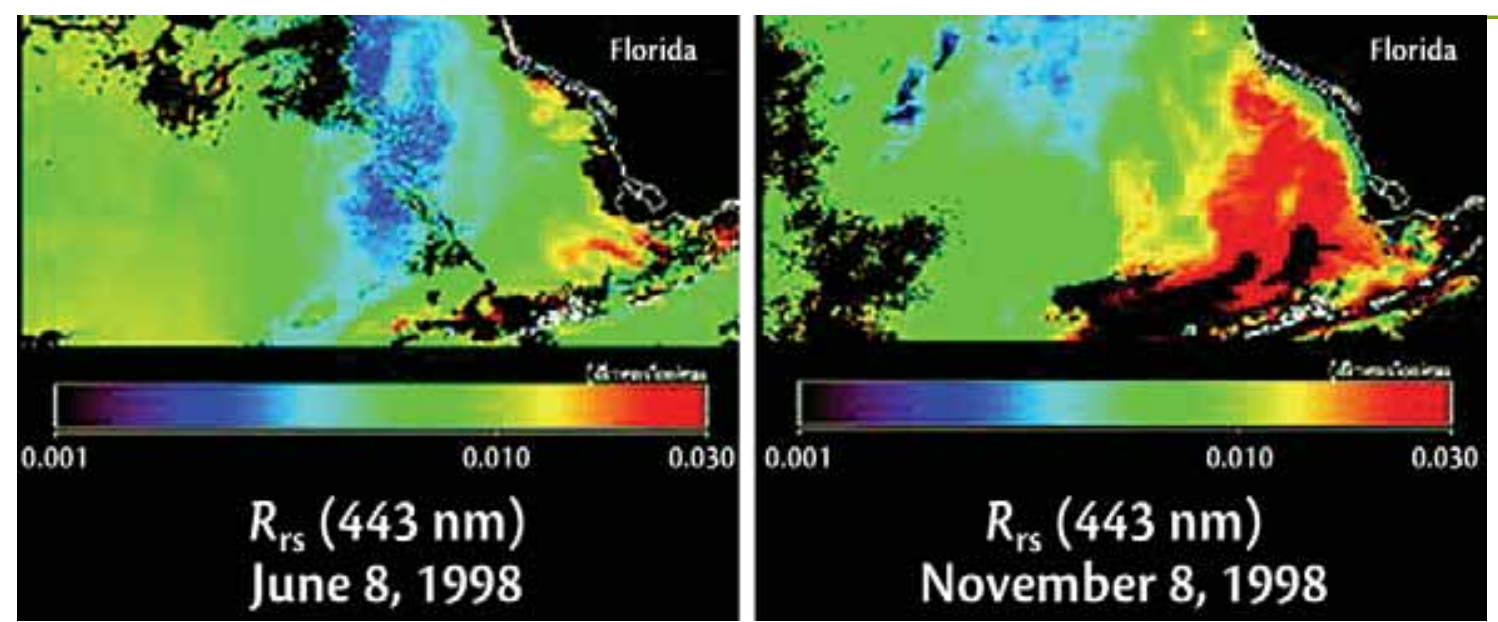

Figure 3. This satellite image shows the optical consequence of resuspended sediments on remote-sensing reflectance. The left panel shows the SeaWiFS $R_{r s}$ at $443 \mathrm{~nm}$ for the West Florida Shelf on June 8,1998 , when the water was generally Case 1. Land and clouds are black; the southern tip of Florida is at the upper right. The right panel is the same scene on November 8, 1998, after Tropical Storm Mitch passed over Florida. The high reflectance (red area) at the right of the figure is believed to be due to increased scattering by storm-resuspended sediments in these shallow waters. 


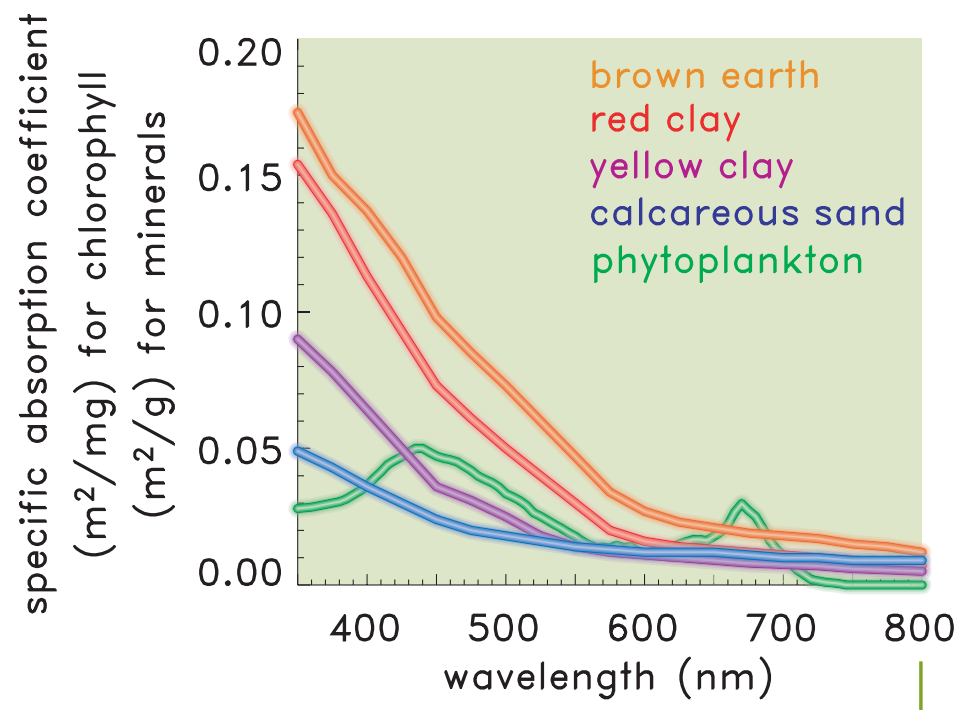

Figure 4. Mineral particles have absorption and scattering properties much different than those of living phytoplankton. Shown here are example specific absorption coefficients (absorption per unit mass concentration of minerals or chlorophyll) for mineral particles and for chlorophyll-bearing phytoplankton. These values, when multiplied by the mineral or chlorophyll concentration, give the absorption coefficient. The mineral spectra are from Ahn (1990); the phytoplankton spectrum is based on Prieur and Sathyendranath (1981).

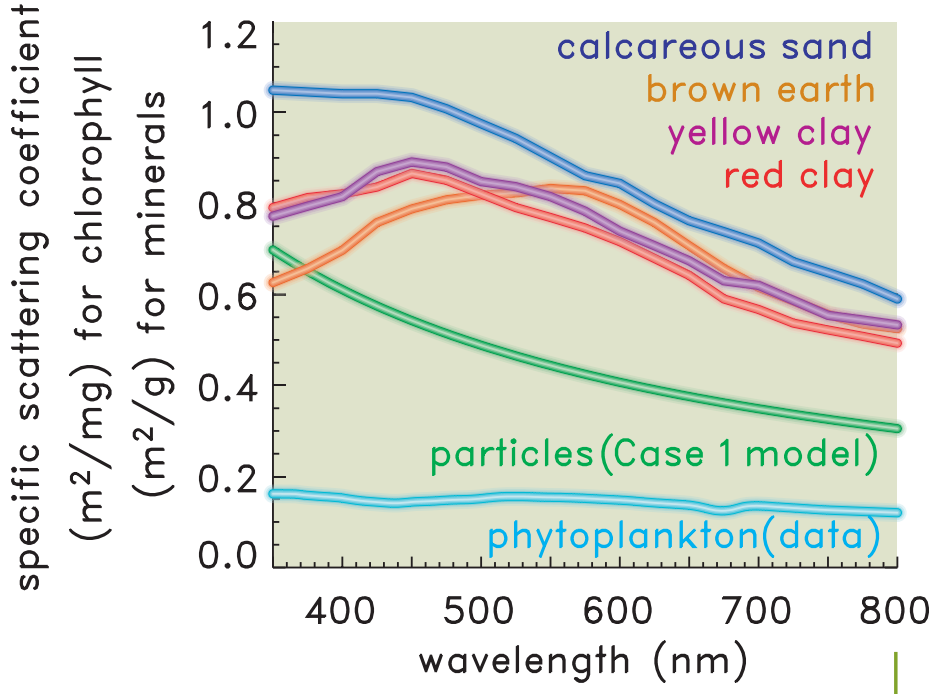

Figure 5. Shown here are the mass-specific scattering coefficients for mineral particles from Ahn (1990); the chlorophyll-specific scattering coefficient for particles from the model of Loisel and Morel (1998) for near-surface Case 1 waters, and the average chlorophyll-specific scattering coefficient of 16 phytoplankton species based on experimental data of Stramski et al. (2001). is available at Sequoia Scientific, Inc.'s web site: www.hydrolight.info). The bottom was taken to be a biofilm-covered ooid sand at 5 $\mathrm{m}$ depth, typical of the area where the IOPs were measured. The sun was at 45 degrees in a clear sky whose atmospheric conditions were typical of those in the Bahamas. We see that $R_{r s}$ is strongly coupled with the tide and is less than would be expected using a model for Case 1 water with the same chlorophyll concentration and bottom and sky conditions. At low tide, $R_{r s}(400 \mathrm{~nm})$ is only onefourth of what would be expected for Case 1 water. Because of the bottom reflectance, these $R_{r s}$ spectra are much greater than the corresponding spectra for optically deep water; the lowest curve shows $R_{r s}$ for the Case 1 IOPs and an infinite bottom depth. As illustrated here, forward numerical models such as Hydrolight or Monte Carlo codes can simulate any water body without difficulty, given the needed input information on the IOPs and bottom reflectance. The difficulty lies in knowing the constituent types, con- centrations, and mass-specific IOPs, and the bottom reflectance in shallow water.

The situation is much more difficult for inverse modeling, i.e., for extracting environmental information from optical measurements made in mineral-laden or optically shallow waters. Empirical models for the explicit inversion of $R_{r s}$ to get the chlorophyll concentration or other environmental information are often designed and tuned for deep Case 1 waters (e.g., the SeaWiFS chlorophyll algorithms; O’Reilly et al., 1998) and fail in shallow waters or waters with high CDOM or mineral concentrations. Semianalytical models based on radiative transfer theory (Maritorena, et al., 2002) can be applied to a wider range of environments. Other methodologies including derivative analysis (Andréfouët et al., 2003; Louchard et al., 2003a), neural networks (Sandidge and Holyer, 1998), and spectrum matching (Louchard et al., 2003b; Mobley et al., 2004) have been used for the analysis of remotelysensed data in mineral-laden or optically shallow waters (see also Philpot et al., 2004).
These methodologies often require hyperspectral data to separate water-column and bottom features (Lee and Carder, 2002).

If coupled physical-biological-optical ecosystem models are to account for the optical effects of resuspended sediments, for example, then physical circulation models must include the ability to predict sediment resuspension. Likewise, if ecosystem models are to include the effects of terrigenous inputs, then coastal-ocean circulation models must be coupled to hydrography models capable of predicting the CDOM and mineral runoff from adjacent land areas. The development of such coupled models is an exciting task for the next few years and abandoning the artificial distinction between Case 1 and 2 waters will hasten their development.

\section{ACKNOWLEDGEMENTS}

The authors thank the Environmental Optics Program of the Office of Naval Research for support during the HyCODE program. Curtiss O. Davis provided helpful comments on a draft of the paper. 四 


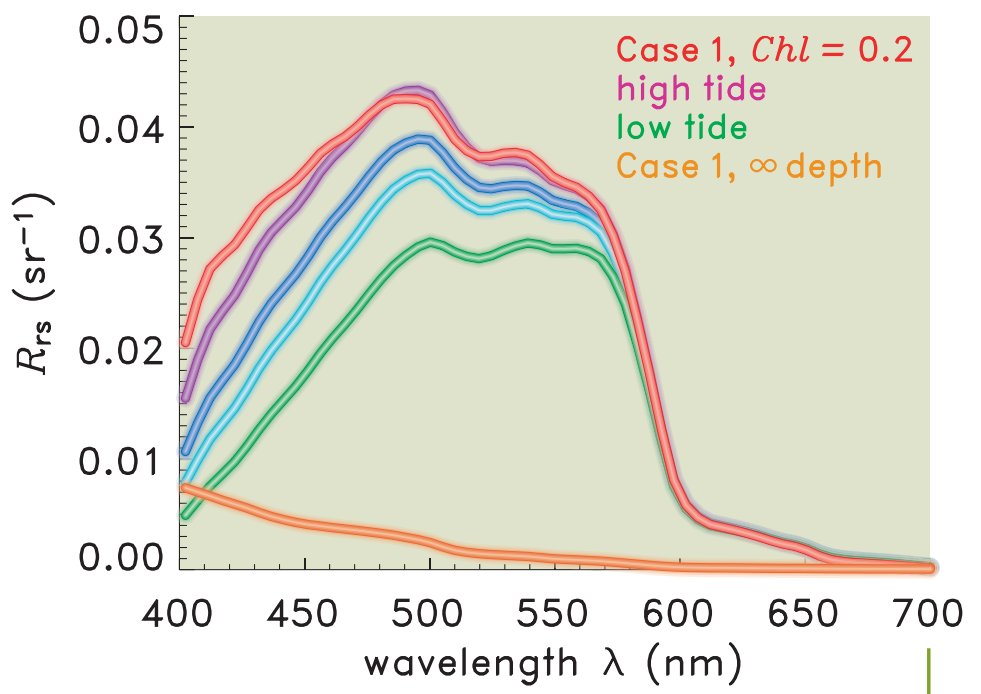

Figure 6. This figure illustrates both water-column and bottom effects on the remotesensing reflectance $R_{r s}$. Here $R_{r s}$ was computed by Hydrolight using the absorption and scattering coefficients of Figure 1 and 2 and a biofilmed sand bottom at $5 \mathrm{~m}$ depth (colored curves). The lowest curve is for the same Case 1 IOPs as the red curve, but for an infinitely deep water column. The curves for the $5 \mathrm{~m}$ bottom are much larger than for the infinitely deep case because of bottom reflectance. The variability in the shallowbottom curves is due primarily to the variation in the CDOM concentration over the tidal cycle and the associated variation in the absorption coefficients as seen in Figure 1.

\section{REFERENCES}

Andréfouët, S., C. Payri, E.J. Hochberg, L.M. Che, and M.J. Atkinson, 2003: Airborne hyperspectral detection of microbial mat pigmentation in Rangiroa atoll (French Polynesia). Limnol. Oceanogr. 48(1, part 1 ), 426-430.

Ahn, Y-H., 1990: Propriétés optiques des particules biologiques et minérales présentes dans l'océan; Application: Inversion de la réflectance. Ph.D. Dissertation, Univ. Pierre et Marie Curie, Paris, France, 214 pp.

Babin, M., and D. Stramski, 2004: Variations in the massspecific absorption coefficient of mineral particles suspended in water. Limnol. Oceanogr., 49(3), 756-767.

Babin, M., A. Morel, V. Fournier-Sicre, F. Fell, and D. Stramski, 2003: Light scattering properties of marine particles in coastal and open ocean waters as related to the particle mass concentration. Limnol. Oceanogr., 48(2), 843-859.

Balch, W.M., J.M. Vaughn, D.T. Drapeau, B.C. Bowler, E. Booth, C.L. Vining, J.F. Novotny, and J.I. Goes, 2004: Case I/II ambiguities in algal blooms: The case for minerals and viruses. American Society of Limnology and Oceanography/The Oceanography Society, Ocean Research 2004 Conference, Honolulu, February 2004.

Bissett, W.P, J.J. Walsh, D.A. Dieterle, and K.L. Carder, 1999a: Carbon cycling in the upper waters of the Sargasso Sea: I. Numerical simulation of differential carbon and nitrogen fluxes. Deep-Sea Res. I, 46, 205-269.

Bissett, W.P, J.J. Walsh, D.A. Dieterle, and K.L. Carder, 1999b: Carbon cycling in the upper waters of the Sargasso Sea: II. Numerical simulation of apparent and inherent optical properties. Deep-Sea Res. I, 46, 271-317.

Bissett, W.P, O. Schofield, S. Glenn, J.J. Cullen, W.L. Miller, A.J. Plueddemann, and C.D. Mobley, 2001: Resolving the impacts and feedbacks of ocean optics on upper ocean ecology. Oceanography, 14, 30-49
Boss, E., and J.R.V. Zaneveld, 2003: The effect of bottom substrate on inherent optical properties: Evidence of biogeochemical processes. Limnol. Oceanogr., 48(1, part 2), 346-354.

Bricaud, A., A. Morel, and L. Prieur, 1981: Absorption by dissolved organic matter of the sea (yellow substance) in the UV and visible domains. Limnol. Oceanogr., 26(1), 43-53.

Gordon, H., and A. Morel, 1983: Remote Assessment of Ocean Color for Interpretation of Satellite Visible Imagery: A Review. Lecture Notes on Coastal and Estuarine Studies, Vol. 4, Springer Verlag, New York, 114 pp.

Gordon, H., O.B. Brown, R.H. Evans, J.W. Brown, R.C. Smith, K.S. Baker, and D.K. Clark, 1988: A semianalytic radiance model of ocean color. J. Geophys. Res. 93(D9), 10,909-10,924.

Lee, Z.P., and K.L. Carder, 2002: Effects of spectral-band number on retrievals of water column and bottom properties from ocean-color data. Appl. Optics, 41(12), 2191-2201.

Loisel, H., and A. Morel, 1998: Light scattering and chlorophyll concentration in case 1 waters: A reexamination. Limnol. Oceanogr., 43(5), 847-858.

Louchard, E., R.P. Reid, F.C. Stephens, C.O. Davis, R.A. Leathers, T.V. Downes, and R.A. Maffione, 2003a: Derivative analysis of absorption features in hyperspectral remote sensing data of carbonate sediments. Optics Express, 10(26), 1573-1584.

Louchard, E., R.P. Reid, F.C. Stephens, C.O. Davis, R.A. Leathers, and T.V. Downes, 2003b: Optical remote sensing of benthic habitats and bathymetry in coastal environments at Lee Stocking Island, Bahamas: A comparative spectral classification approach. Limnol. Oceanogr., 48(1, part 2), 511-521.
Maritorena, S., D. A. Siegel, and A. R. Peterson, 2002: Optimization of a semianalytical ocean color model for global-scale applications. Appl. Optics, 41(15), 27052714 .

Maritorena, S., D. A. Siegel, and J. E. O’Reilly, 2004. Optical properties of oceanic Case 1 waters: Still an issue!! American Society of Limnology and Oceanography/ The Oceanography Society, Ocean Research 2004 Conference, Honolulu, February 2004.

Mobley, C.D., and D. Stramski, 1997: Effects of microbial particles on oceanic optics: Methodology for radiative transfer modeling and example simulations. Limnol. Oceanogr., 42(3), 550-560.

Mobley, C.D., L.K. Sundman, C.O. Davis, T.V. Downes, R.A. Leathers, M. Montes, W. P. Bissett, D.D.R. Kohler, R.P. Reid, and E.M. Louchard, 2004: Interpretation of hyperspectral remote-sensing imagery via spectrum matching and look-up tables. Appl. Optics, submitted.

Morel, A., 1988: Optical modeling of the upper ocean in relation to its biogeneous matter content (Case 1 waters). J. Geophys. Res., 93(C9), 10749-10768.

Morel, A., and S. Maritorena, 2001: Bio-optical properties of oceanic waters: A reappraisal. J. Geophys. Res., 106(C4), 7163-7180.

Morel, A., and L. Prieur, 1977: Analysis of variations in ocean color. Limnol. Oceanogr., 22(4), 709-722.

Morel, A., D. Antoine, and B. Gentili, 2002: Bidirectional reflectance of oceanic waters: accounting for Raman emission and varying particle scattering phase function. Appl. Optics, 41(30), 6289-6306.

O’Reilly, J.E., S. Maritorena, B.G. Mitchell, D.A. Siegel, K.L. Carder, S.A. Garver, M. Kahru, and C. McClain, 1998: Ocean color chlorophyll algorithms for SeaWiFS. J. Geophys. Res., 103(C11), 24937-24953.

Philpot, W., C.O. Davis, W.P. Bissett, C.D. Mobley, D.D.R. Kohler, Z. Lee, W.A. Snyder, R.G. Steward, Y. Agrawal, J. Trowbridge, R. Gould, and R. Arnone, 2004: Bottom characterization from hyperspectral image data. Oceanography, this issue.

Prieur, L., and S. Sathyendranath, 1981: An optical classification of coastal and oceanic waters based on the specific spectral absorption curves of phytoplankton pigments, dissolved organic matter, and other particulate materials. Limnol. Oceanogr., 26(4), 671-689.

Sandidge, J.C., and R.J. Holyer, 1998: Coastal bathymetry from hyperspectral observations of water radiance. Remote Sens. Environ., 65(3), 341-352.

Smith, R.C., and K.S. Baker, 1978. The bio-optical state of ocean waters and remote sensing. Limnol. Oceanogr., 23(2), 247-259.

Stramski, D., and C. D. Mobley, 1997: Effects of microbial particles on oceanic optics: A database of singleparticle optical properties. Limnol. Oceanogr., 42(3), 538-549.

Stramski, D., A. Bricaud, and A. Morel, 2001: Modeling the inherent optical properties of the ocean based on the detailed composition of planktonic community. Appl. Opt., 40(18), 2929-2945.

Stramski, D., S.B. Wozniak, and P.J. Flatau, 2004: Optical properties of Asian mineral dust suspended in seawater. Limnol. Oceanogr., 49(3), 749-755. 